\title{
THE AUTHENTIC SUBDIVISIONS OF DAYTIME AND NIGHT AMONG THE TZOTZIL REJECTION OF A POPULAR MODEL OF THE UNIVERSE
}

\author{
Ulrich KOLHER \\ Universität Freiburg/Br.
}

\section{The Problem}

This paper examines Tzotzil concepts on day and night and how they are subdivided. In order to understand the indigenous cognitive system it is important to clarify where the sequence begins and to determine the periods and/or points ${ }^{1}$ within it, their lengths and how they are delimited from each other. If the phases are conceived of metaphorically, it is an additional goal of the investigation to show how the various metaphoric images are distributed throughout the sequence.

The principle question regards the possible existence of a pre-Columbian subdivision of day and night which is comparable to the Western division of the day into hours.

Such a system of reckoning time was postulated by Holland (1963: $70 ; 1964: 15)$ for the Tzotzil of Larrainzar and —almost a hundred years ago - by Seler (1902-1923, IV: 30ff.) for the Aztec and other peoples of Central Mexico. ${ }^{2}$ Neither, however, provided indigenous expressions for their "hours" in the respective languages. Such linguistic material will be presented here from four "municipios" (counties) of the Tzotzil, including the one where Holland developed his model.

The Tzotzil live in the highlands of Chiapas in southeastern Mexico and speak one of the Mayan languages. They are known to be one of the least acculturated ethnic groups of Mesoamerica. The preservation of traditional ways holds also for their manner of reckoning time,

${ }^{1}$ Periods are defined as lengthy stretches of time, points as brief moments in time.

${ }^{2}$ Apparently Holland was not aware of Seler's interpretation. 
since they still use the pre-Columbian subdivision of the year (which is divided into eighteen periods of twenty days and one of five) as well as the ancient vigesimal system of counting. Their preoccupation with matters of time is also attested to by the fact that the most detailed subdivision of the lunar cycle known to present for Mesoamerica was recorded among them (cf. Köhler 1982, 1991).

The Tzotzil are, thus, an excellent starting point for exploring indigenous Mesoamerican concepts of time, such as the subdivision of daytime and night. A comparison with published data shows that the basic pattern of the Tzotzil holds true for other Mayan groups and as well as for the Aztec, Maya and Zapotec of the 16th century. ${ }^{3}$ The importance of the linguistic data presented here lies in the detailed description of a complete sequence of daytime and night, which also indicates alternative names for particular phases.

In a more general framework, the Tzotzil subdivision of time may help us better understand the Mesoamerican image of the universe or, at least, parts of it. Regarding the way the various skies are ordered with respect to each other, Seler and Holland postulated upward and downward steps, representing hours in the diurnal and nocturnal movement of the sun. In the version of Holland (figure 3) this model has been well received in North America and Mexico, and, at least, six colleagues have published slightly altered versions of it (Villa Rojas, 1968: 146; Vogt, 1969: 601; Heyden, 1973: 110; Tibón, 1981: 207; Lowe, 1982: 274; Florescano, 1992: 26). This model presupposes the existence of hours of equal length as in the modern European concept. The linguistic data will show whether this is the case or not.

In the following, I present the source material in full detail so that even slight variations become apparent. The material is presented and coded such that the version of each individual informant, including his idiosyncrasies, remains clear. Examining the literature quoted in Munn's recent article "The Cultural Anthropology of Time" (1992), no description of similar transparence could be detected.

The method employed here permits valuable insights for cognitive anthropology and linguistics. With its analytical frame of reference (Table 1), which may be altered according to the respective culture, the existing emic criteria and their distribution throughout daytime and night become apparent. Due to this approach the article is also a general contribution to methods in the anthropology of time. ${ }^{4}$

${ }^{3}$ The references are given towards the end of the paper.

${ }^{4}$ As a matter of fact, the theme of how daytime and night are subdivided is as such 


\section{The Sources}

I collected all the material presented in this paper in August, 1976, in the "municipios" of San Pablo Chalchihuitán, Chenalho and Larrainzar, except that from informant (A), whom I interviewed in August, 1971. To present a more complete picture I have included all terms relevant to the topic contained in Robert Laughlin's "Great Tzotzil Dictionary of San Lorenzo Zinacantan" (1975). The data from the field and the dictionary are not entirely comparable with each other, since I asked informants to consecutively name all subdivisions of day and night, while the dictionary entries were mainly generated by exploring the productivity of linguistic roots. Information from two informants (A and F) was taped, the rest was noted in field journals. All interviews were conducted in Tzotzil.

The code letters $\mathrm{A}$ to $\mathrm{H}$ refer to individual Tzotzil men with whom I consulted, and $\mathrm{Z}$ to Laughlin's dictionary data which he obtained from Zinacantan. Informants (A) through (E) were Pablero, informant $(F)$ Pedrano, and $(\mathrm{G})$ and $(\mathrm{H})$ Andresero. ${ }^{5}(\mathrm{~A})$ was a respected elder, about 65 years of age in 1971, from the Sisim area; (B) also an elder from Sisim, about 45 years old when interviewed in 1976; (C) about 25 years old, from Tzak'uk'um; (D) about 30 years old, from Balunako (together with others from his area who also contributed comments); (E) three brothers in their twenties from Pom who gave joint statements; $(\mathrm{F})$ a repected curer from Chenalho in his middle forties; $(\mathrm{G})$ and $(\mathrm{H})$ both from Larrainzar, aged, respectively, about 43 and 33 .

Following each Tzotzil term listed below is a code in parentheses: the capital letters allude to the informant, the numbers indicate the sequence of his terms and small letters (a to c) represent alternative expressions by the respective person. All terms listed under the initial numbers 1$), 2$ ), 3), etc. pertain to that particular phase. ${ }^{6} \mathrm{~A}$ phase is defined as a separate unit in the sequence and can either be a point or a period. By this presentation each individual sequence can easily be reconstructed.

a neglected field. It seems symptomatic that this subject is not explicitly treated in Barbara Tedlock's "Time and the Highland Maya" (1992) nor in Alfred Gell's general study "The Anthropology of Time" (1992).

${ }^{5}$ These are ethnonymes for inhabitants of San Pablo and the predominant Indian groups of San Pedro Chenalho and San Andres Larrainzar.

6 The numeration is mine and only serves the purpose of identifying particular phases under discussion. To simplify the identification, the list of terms is treated as one sequence, although there are certain indications that the Tzotzil consider day and night as separate entities. 
Occasionally, my consultants, without being asked, supplied a European equivalent in hours, which is also included in the list below. I, however, did not pursue these statements further. An asterisk indicates which informant provided the hour equivalent when identical terms were given by several informants. These references to hours should be regarded as vague guesses, since at that time watches were used by only a few individuals.

1)a. kahtzah htotik (A1a)
b. kahtzah tal htotik (A1b)
c. kahtzah xa htotik (B1)
d. lok' tal htotik (C1, H1*)
e. xklok' htotik - som' (D1a)
f. lok' xa htotik (D1b)
g. xlok' tal htotik
h. xlok' tal htotik (F1a)
i. lok' ssat htotik (F1b)
j. lok' xa tal htotik (G1)
k. t xtal xa k'ak'al (Z1)

2)a. toyol xa htotik (A2,B2a, $\mathrm{C} 2 *, \mathrm{E} 2)$

b. bavitzah xa htotik (B2b)

c. toyol xa k'ak'al (D2, G2)

d. t xkahtzah li k'ak'al ta ba vitz (Z2a)

e. itoy xa k'ak'al (Z2b)

f. toyol k'ak'al (Z2c)

3)a. vato xa htotik (B3)

b. nona k'ak'al (H2)

4)a. li' sk'an o'lk'ak'al (A3)

b. stahobal o'lk'ak'al (D3)
9:00

9:00

8:00

our father rose

our father rose hither

our father rose already

our father came out hither

our father comes out - dawn

our father came already out

our father comes out hither

- dawn time

our father comes out hither

our father's face came out

our father came alr. out

hither

sun/day is already coming

$(330)^{7}$

our father is already high

our father ascended already

day/sun is already high

the sun is rising to the top of the mountain $(164)^{8}$ sun/day rose high alr. (345) sun/day is high (346)

our father is already

at one fourth

nona ${ }^{9}$ day/sun

this (gesture) lacks till midday

$11: 00$

on verge of approaching midday

${ }^{7}$ These numbers refer to page numbers in Laughlin's dictionary.

${ }^{8}$ It is clear from the context that here only the sun is referred to.

${ }^{9}$ Unintelligible word, possibly of European origin ("novena"?). 
c. po'ot o'lk'ak'al (G3)
d. hutuk xa sk'an o'lk'ak'al (G4)

5) a. stah o'lk'ak'al (A4)

b. o'lol htotik (B4)

c. o'lk'ak'al (C3, G5a, Z3b)

d. stah xa o'lk'ak'al (D4)

e. o'lol k'ak'al - tax'ech' htotik (E3)

f. o'lol htotik xa (F2) - tax'ok' kotz

g. o'lol xa k'ak'al (G5b)

h. o'lol k'ak'al (H3, Z3a)

6) a. ni'p'uh htotik (A5)

b. tz'e'p'uh xa htotik (C5*, F3c, H4b)

c. ni'p'uh xa htotik (D5*, F3a)

d. tz'e'p'uh xa k'ak'al (G6)

e. xtixet k'ak'al (H4a)

f. bat ${ }^{13} \mathrm{xa}$ htotik $(\mathrm{E} 4, \mathrm{~F} 3 \mathrm{~b})$

g. xtz'e'et k'ak'al (Z4a)

h. itz'e'p'uh k'ak'al (Z4b)
9-10:00 ${ }^{10}$ almost midday

little lacks alr. till midday

reaches midday

our father is in the center ${ }^{11}$

midday (64)

reaches already midday

midday - our father

passes by (or through)

our father is alr. in the center

- cock crows then

already midday

midday (64)

our father bent down

13:00

our father turned aside

(over) $)^{12}$

13:00

15:00

14:00

our father bent already down

day/sun turned alr. aside

day/sun moves down

our father leaves already

sun turns aside (101)

sun turned aside (101)

${ }^{10}$ This temporal assignation cannot be accurate. Based on the semantic content, term G3 is grouped here with the other terms signifying "just before noon". Term G4 is then a slight variation within this phase and signifies "approaching even closer to noon". No hour was mentioned for G4.

${ }^{11}$ In Western terminology "center" would be meridian. A similar term is used to describe the two quarters of the moon when it is in the middle of its orbit at dusk or dawn (cf. Köhler, 1982: 32-33).

12 This alternative description of the sun's movement holds also for the terms $6 \mathrm{~d}$, $6 \mathrm{~g}$, $6 \mathrm{~h}$ and, with reference to the movement of the night, for the phase after midnight $16 \mathrm{~b}, 16 \mathrm{c}, 16 \mathrm{~d}, 16 \mathrm{f}, 16 \mathrm{~g}, 16 \mathrm{~h}, 16 \mathrm{i}, 16 \mathrm{j}$. Translating the Tzotzil terms into English, I followed the rendering in Laughlin's dictionary (1975). In August 1993, asking consultants in San Pablo, Chenalho and Pantelho, I was able to get additional information on the meanings of $n i^{\prime} p^{\prime} u h$ and $t z^{\prime} e^{\prime} p^{\prime} u h$. The word ni'p'uh was described as a downward movement, usually in the form of an arch (like a branch of a tree), $t z^{\prime} e^{\prime} p$ 'uh as tipping over (like a bottle or a pole). They are considered as close synonyms. One Pablero explained the slight difference using a chair: tipping it toward its front is ni'p'uh, toward its side $t z^{\prime} e^{\prime} p^{\prime} u h$. All informants stated that both words refer to a downward movement, never to an upward.

${ }^{13}$ Here, and also in the following phase the words bat and mal grammatically seem to refer to a past action, yet it is clear that the activity still continues. Thus bat seems to function as an abreviation for xbat. The same applies for mal. 
7) a. bat xa htotik (A6, B5, C5*) 15:00

b. bat xa tek htotik (D6)

16-17:00

our father leaves already

c. stah xa o'lol syalel(E5) 15:00 our $f$. leaves alr. indeed

d. bat xa k'ak'al (G7) he reaches already the middle of his descent

e. xalbe k'ak'al (H5a) 16:00

f. mal k'ak'al (H5b) day/sun leaves already

g. mal xa k'ak'al (Z5a)

h. mal xa (Z5b)

i. xmalet k'ak'al (Z5c)

8) hlikel xa sk'an xch'ay (D7)

9) a. bat htotik un (A7) 16

b. ch'ay o xa htotik (D8)

c. taxch'ay xa htotik (E6,F4)

d. chch'ay htotik (H6)

e. ich'ay hch'ul-totik (Z6)

10) a. ik'um'xa (A8)

b. ik' xa osil - mo xa xkil htotik (B6)

c. ik' xa - sabet xa osil (C6)

d. ik' xa - mo xkil htotik (D9)

e. ik' xa osil (G7)

f. orasyon osil - hutuk xa xkil (H7)

g. yik'ubal osil (Z7)

11) a. yochil ak'obal (B7)

b. likel yik'obal (C7)

$x$ albe $e^{14}$ day/sun

day/sun flows away ${ }^{15}$ sun flows already away

flows already away sun is flowing away (227)

a little lacks already till he disappears

our father left then our father has already entirely disappeared our $\mathrm{f}$. is alr. disappearing our father is disappearing our holy father disappeared getting already dark already dark time - we do not see our $f$. any more already dark - already sabet ${ }^{17}$ time already dark - we do not see our father already dark time prayer time - we see just a little time of getting dark (58)

entering of night beginning of its darkness

${ }^{14}$ Unintelligible word, probably wrongly noted in diary.

${ }^{15}$ Alternative translation "spills away". This applies also for phases $7 \mathrm{~g}, 7 \mathrm{~h}, 7 \mathrm{i}$.

${ }^{16}$ It cannot be entirely excluded that this is a variation of $7 \mathrm{a}$.

${ }^{17}$ Unintelligible word. Possibly it is derived from som', which designates the early morning. In that case the common semantic base would be twilight. There could also be a relation to the term samelsamel osil, which designates "late afternoon" in an early Tzotzil dictionary and to samel which has that same meaning among the modern Tzotzil of Venustiano Carranza (Laughlin, 1988, I: 295). 
c. ak'obaltik xa (E7)

d. stah xa ochel ak'obal (F5)

e. och ak'ubal

ik' xa balamil (H8)

f. $\operatorname{nax}^{18}$ yik'ubel (Z8)

12) $\operatorname{naxnax}(\mathrm{Z9})$

13) a. nax xa ak'obal (A9)

b. nax xa hutuk ak'obal (C8) 21:00

c. nax ak'obal (D10*, E8, F6) 21:00

d. nax ak'ubal (H9*, Z10*)

e. naxum' xa ak'ubal - xihvaykutik (G8)

14) a. tahobal o'l'ak'obal (A10)

b. sk'an hutuk o'l'ak'obal (C9)

c. stahobal xa o'l'ak'obal

(D11)

15) a. o'l'ak'obal (A11, B8, C10)

b. o'l'ak'obal xa

$$
\text { - xu' xa xihvay (D12) }
$$

c. stah xa o'lol ak'obal (E9)

d. o'lol ak'obal (F7)

- k'ok'oro xi kotz tok

e. o'lol ak'ubal' ${ }^{19}(\mathrm{G} 9, \mathrm{H10}, \mathrm{Z11a})$

f. o'l'ak'ubal (Z11b)

16) a. ni'p'uh xa ak'obal (A12)

b. tz'e'p'uh xa ak'obal (B9)

c. tz'e'p'uh xa ak'obal - x'ok' xa kaxan (C11)

d. tz'e'p'uh xa ak'obal - x'ok' xa kotz (D13)

e. x'ok' kotz - sba'ok'olal kotz (E10)

f. tz'e'p'uh xa o'lol ak'ubal (F8) already nighttime reaches alr. entering night night entered - world is already dark

20-21:00 late dark getting (58)

21:00 rather late (249)

night is already advanced

$\mathrm{n}$. is alr. a little adv.

night is advanced

night is advanced (249)

night is already advancing - we sleep

on verge of reaching midnight

little is left till midnight already on verge of reaching midnight

midnight already midnight - we must sleep now already reaches midnight midnight - cock says also "k'ok'oro"

midnight (64) midnight (64)

night already bent down night alr. turned aside night alr. turned aside - chicken crows already night alr. turned aside - cock crows already cock crows - first crowing of cock midn. alr. turned aside

${ }^{18}$ The word nax usually stands for actions which occurred earlier on the same day. In the nocturnal context it stands, however, for late or advanced, although I have not yet detected a semantic bridge between these two meanings.

19 The versions $a k^{\prime}$ obal and $a k^{\prime} u b a l$ apparently reflect differences in dialect, the former is used in San Pablo, the latter in Larrainzar and Zinacantan, while my consultant from Chenalho used both terms. 

g. tz'e'p'uh xa ak'ubal (G10)
1-2:00 night alr. turned aside
h. stz'e'et ak'ubal (H11)
3:00 night turns aside (101)
i. xtz'e'et ak'ubal (Z12a)
1-2:00 night turns aside (101)
j. itz'e'p'uh ak'ubal (Z12b)
1-2:00 night turned aside

17) a. ok' xa kotz (A13, B10)

b. xcha'ok'olal kaxan (C12)

cock crowed already

c. sni'p'uh ak'obal

- xcha'ok'olal kotz (E11)

18) a. xcha'ok'olal kotz (A14, B11)

b. yoxok'olal kaxan (C13)

second crow of chicken

night bends down

- second crow of cock

19) a. yox'ok'olal kotz (A15a, B12a) ${ }^{20}$

b. sakobal (A15b)

c. sakum' xa osil (B12b)

d. sk'an ssakum' (C14)

e. sakum' xa

- yox'ok'olal kotz (E12)

f. hutuk sk'an tzsakum' (F9)

second crow of cock

third crow of chicken

third crow of cock

getting light

alr. time of getting light

it wants to get light

already getting light

third crow of cock

little lacks till getting light

20) a. sak xa - k'al toyol

muk'ta k'anal (B13)

b. sak xa (C15)

c. sakobal xa (D14a)

already light

- when big star is high

already light

already on the verge of getting light

d. sak xa

- xu' xihbat ta am'tel (D14b)

already light

- we must go to work

e. sakum' xa (F10)

f. po'ot xa sakum'(G11)

g. po'ot xa sakum'

- tzoh xa vinahel (H12)

h. ssakum' (Z13a)

i. sakubel osil (Z13b)

already getting light

alr. almost getting light

alr. almost getting light

- sky is already red

it is getting light (304)

time of getting light (304)

21) a. tzoh vinal - sakhaman xa osil balamil (A16)

b. tzoh vinahel

- chapulan ta vinahel (B14)

c. tzoh vinahel (C16)

d. tzoh xa vinahel (D15, E13)

sky is red - world is alr. suffused with white sky is red - keep getting ready in heaven ${ }^{21}$

sky is red

sky is already red

${ }^{20}$ In his second version of the cycle, informant (A) also added xchan'ok'olal and yo'ok'olal kotz, the fourth and fifth cock-crow, and then equated the latter with sakobal.

${ }^{21}$ It is not indicated who is getting ready. 
e. tzoh xa vinahel

- toh toyol xa k'anal (F11)

22) a. sak xa un (A17)

- xibat hk'el kam'tel

b. sak xa osil (G12a)

c. sakhaman $x a(G 12 b)$

d. tzoh vinahel (G12c)

e. sak osil (H13a)

f. sak xa me un (H13b)

g. lek sak xa li osile (Z14) sky is already red

- star is already very high

already clear then - I go

to look after my work

environment is alr. clear

alr. suffused with white

sky is red

environment is clear

already clear then indeed

already nicely clear the

environment (302)

In addition to the terms listed above, others exist for the period between sunrise and sunset. They are indicated by a gesture to the position of the sun on its orbit and accompanied by the words xi htotik, "thus our father", or le' htotik, "there our father". They are of practical use for fixing appointments.

\section{Discussion}

\section{Individual Variation}

The terms listed above convey a picture of considerable individual variation in expressing one and the same idea. The great variety is particularly evident for the phases of sunrise (1), early and advanced afternoon $(6,7)$, as well as the phase after midnight (16). Considering the numerous descriptions for each phase, we may conclude that it is the idea characterizing a particular phase which is learned during enculturation and not a specific terminology.

\section{Pattern of Subdivision}

Although the data was collected in four different "municipios", a general pattern emerges, which becomes even clearer when one discards concepts obviously based on European or Christian influence, such as phase 3 and terms referring to the crowing of cocks. ${ }^{22}$ We are left then with the following major phases, all reported by several consultants:

${ }^{22}$ In phase 3 the first term vato is derived from the Spanish "cuarto", indicating the first quarter of daytime; the second term seems to be of European origin as well (see footnote 9). The notion of three cock-crows obviously is a Christian intrusion. 
The rising of our father.

His position high in the sky.

Approaching midday.

Midday.

Our father bends down.

Our father already leaves.

Our father disappears.

Getting dark.

Entering night.

Advanced night.

Time before midnight. ${ }^{23}$

Midnight.

Night having bent down.

Approaching dawn.

Already light.

Red sky.

Already clear.

If we leave the cock-crows in the list, then the sequence of terms between midnight and sunrise is not entirely clear, since the cock is reported to crow at various times. Evidently there is no general agreement as to when the cock crows. A consistent picture emerges if we ignore the cock-crowing: after midnight comes "night having bent down or turned aside", which is followed by four descriptions of progressively increasing lightness.

Regarding their relative importance, certain phases, such as sunrise, noon and midnight, received considerable attention, as one would expect. Not so sunset, however, which was mentioned only in six of nine statements (and one of these is doubtful). However, using similar expressions, almost all informants referred to the high position of the sun in the morning, the two phases of its descent in the afternoon and the time after midnight.

Looking at the amount of phases within each quarter certain differences become evident. Three or four phases are recognized for morning and afternoon although the majority of informants give only two for each. Between sunset and midnight there are three to four phases, and between midnight and sunrise, four to five or even more. Thus more terms exist for the period when the sun god is absent than when

${ }^{23}$ This term was reported only from San Pablo. 
present. ${ }^{24}$ Several explanations for this are possible. 1) More terms may be required during the sun god's absence which otherwise could be expressed with the term xi htotik, "thus our father" (sun god), and an accompanying gesture of the arm..$^{25}$ 2) The different shadings of light intensity and colors during dawn and dusk offer easy criteria for establishing phases. 3) Numerous phases may be useful points of reference for early morning activities which occur at various times, such as collecting firewood (men), making tortillas (women), preparing for work (men) and feeding animals (women).

Considering the latitude of Mesoamerica it is of particular interest, whether the gestures, by which positions of the sun are indicated during daytime, change in the course of the year. In this area, after all, the sun describes a high northern orbit for about three months in summer, while in winter a low southern orbit (cf. Köhler, 1974). I did not ask about this when collecting the data, but was able to consult Tzotzil informants from San Pablo, Chenalho and Pantelhó in August 1993. Gestures do indeed change with the seasons and always point to the respective position of the sun in the sky. Vogt (n.d.) confirmes this for Zinacantan.

The Beginning of the Count

Establishing the beginning of the Tzotzil sequence may shed light on precisely where the ancient Mesoamerican count began, a matter which is still debated.

Six of my eight informants started the sequence in the morning, one (G) at noon and one (A) after sunset. The latter was probably induced to begin with nighttime terms since my local assistant, in order to explain the topic I was interested in, recited several terms from midnight onward.

Those who started the sequence in the morning did not do so uniformly. Some began with sunrise (D, E, F and H), while others (B and C) began two phases earlier with "getting light" followed by "red sky." No indication of where the sequence begins could be found in the information gleaned from Laughlin's dictionary.

The data strongly indicates that the Tzotzil count starts with sunrise.

${ }^{24}$ In his model Holland had postulated the contrary (figure 3), thirteen phases for daytime and only nine for the night.

${ }^{25}$ This could also explain why the European concept of the cock's crow has been readily accepted as an extention of the original system. 


\section{TABLE 1: CRITERIA FOR DEFINING THE PHASES}

\begin{tabular}{|c|c|c|c|c|c|}
\hline 1 & 2 & 3 & 4 & 5 & 6 \\
\hline $\begin{array}{l}\text { Movement or } \\
\text { position of } \\
\text { sun god }\end{array}$ & $\begin{array}{l}\text { Movement of. } \\
\text { position in } \\
\text { day/night }\end{array}$ & $\begin{array}{l}\text { Bright/dark } \\
\text { or color of } \\
\text { surrounding }\end{array}$ & $\begin{array}{l}\text { Relation } \\
\text { to stars/constell. }\end{array}$ & $\begin{array}{l}\text { Activity } \\
\text { of } \\
\text { animals }\end{array}$ & $\begin{array}{l}\text { Activity } \\
\text { of } \\
\text { people }\end{array}$ \\
\hline
\end{tabular}

1. god rises (3)

god comes out (11)

sun/day comes (1)

2. god is high (4)

god ascends (1) sun/day, ascends (1)

sun/day is high (4)

3. god at $1 / 4$ (1) nona-day 4. almost midday (4)

5. god in center (1)

midday (11) cock crows (1)

god passes by (1)

6. god bent down (3)

god turned aside (3)

god leaves (2)

sun/day turned aside (3)

sun/day moves down (1)

7. god leaves (4)

$1 / 2$-way descended (1)

sun/day leaves (1)

sun/day flows away (4)

xalbe-sun/day (1)

8. almost disappearing (1)

9. god left (1)

god disappears (5)

10.

.

getting dark (6)

sabet-time (1)

enter night (4) already dark

rather late (1)

advanced night (5)

almost midnight (3)

midnight (10)

night bent down (1)

night turned aside (8)

17. night bends down (1)

18.

19.

20.

21. get ready in heaven (1)

22.

red sky (1)

red sky (1) cock crows (1) we sleep (1)

cock crows (2)

1. cock-crow (1)

chicken crows (1)

cock crowed (1)

2. cock-crow (2)

2. cock-crow (1)

3. cock-crow (1)

3. cock-crow (2)

alm. getting light (2)

don't see god

don'tsee much

pray (each 1)

getting light (3)

getting light (6)

alr. light (3) Venus high (1)

we must go to work (1)

red sky (5) star high (1)

world getting clear (1)

alr. clear (6) 
Semantic Categories for Determining Subdivisions

Six categories were employed to assess the 22 phases (listed in Table 1) distributed over the entire sequence.

1) Movement or position of the sun god.

2) State of day or night.

3) Brightness, darkness or color of environs.

4) Position of stars or planets.

5) Activity of animals.

6) Activity of humans.

Terms illustrating the movement or position of the sun god are clearly limited to the period between sunrise and sunset. Only one informant (B) described all daytime divisions with reference to htotik, "our father" (= the sun god), while all others used the term $k^{\prime} a k^{\prime}$ al (= sun/day) for some or most of the divisions.

Translation of the term k'ak'al presents some problems. When the term refers to the sun as the celestial body of the sun god, it belongs to the first category; when it refers to notion of day, it belongs to the second. The cognitive process between these two usages is different. One usage, with a plain statement, describes an observation, "our father / the sun bent down," while the other transposes this observation to the "day" and thus infuses this abstract concept with life. It can be seen that in San Pablo, and to the best of my knowledge also in Chenalho, k'ak'al means "day" and not "sun." It is used only for midday expressions ${ }^{26}$ and belongs to the second category. In Larrainzar (Hurley Vda. de Delgaty et al., 1978: 280,365) and Zinacantan (Laughlin, 1975: 185), however, the term has both meanings, and is placed between categories 1 and 2 in Table 1.

This ambiguity does not exist during the night and expressions of "entering" or "reaching the middle" can only belong to the second category. The term $t z$ 'e'p'uh ak'obal provides an interesting example of how a term originally used for the movement of the sun god can be borrowed for nighttime terms. The transposition is as follows: sun god turns aside, day turns aside, night turns aside.

The terms that refer to the degrees of increasing lightness or darkness are alternately described as processes or situations. They are used only for dawn and dusk. It should not be suprising that the object

${ }^{26}$ The only exception is phase $2 \mathrm{c}$ from informant (D). 
which changes illumination is usually not mentioned. At times, however, the word osil is used, which basically means "land", in a generalized sense, "environment, environs", and in a derived sense, "time". With respect to reckoning time, the latter two translations are best applied. The terms which describe the aurora invariably refer to the red colored sky.

Only two expressions listed here refer to celestial bodies other than the sun: Venus (which is conceived of as a star) and a morning star (which probably refers to a planet). In addition, I have come across expressions which refer to an unspecified morning star for dawn or the period after midnight. Furthermore, one particular definition of midnight alludes to the position of the Pleiades: o'l'ak'obal - ni'p'uh xa xonom', "midnight - Pleiades already bent down". This definition only applies to winter time, and according to the particular winter month, a different position of the Pleiades must be given. ${ }^{27}$

The only animal activity mentioned is the crowing of the cock. It may be assumed that the word kaxan pertains only to the male sex of this domesticated bird. Only those terms for the period between midnight and sunrise mention the cock's crow. One informant, however, used it for noon and for a phase before midnight, but these were supplementary explanations.

The category involving animal activity cannot be equated perfectly with other categories. The main problem stems from the fact that the individual informants assigned the first cock-crow to different phases (and consequently further crowing to following phases). Since turkeys do not crow, references to cock-crowing are of European influence. They are, thus, an alien element which was added to the indigenous concept. All expressions mentioning cock-crowing were from the community of San Pablo. It possibly represents a local concept, widespread in the community, since all informants from that area mentioned it, although they live in different parts of the "municipio".

With one exception, all expressions that are based on human activities were given as supplementary explanations of various phases. They all refer to the time between dusk and dawn. Four activities

${ }^{27}$ Based on fieldnotes collected by Gelwan in 1972, Vogt (n.d.: 17) mentions the example of a Zinacantec who determined moments of the night by referring to Venus and six different constellations. We may assume that similar orientations were also important in other communities before the introduction of modern watches. 
are specified: praying, inability to see the sun anymore, sleeping and pre-dawn work (including early risers and late risers).

Length and Quality of Subdivisions

An important question is to what extent can the different phases of the Tzotzil day and night count be compared to the European system of reckoning by hours. Nowotny $(1976: 47)$ has drawn attention to the fact that Aztec subdivisions of time were by no means hours. He concluded on the basis of linguistic evidence that the terms referred to marks in time (Zeiteinschnitte), which, as I understand him, encompass the idea that there is no innate connection among the different markings.

The material presented here should be subjected to the following questions. Are there actual points in time, and if so, what is the distance between them? Are there, in addition to points, also periods? If so, how long are these periods and what delimits them? Furthermore, how are the possible periods and points connected?

Possible points in time (see figures 1 and 2) are sunrise (1), noon (5), sunset (9), midnight (15), the two half-way positions, mid-morning and mid-afternoon (3a, 7c).

The terms for sunrise and sunset describe the events either as having happened, and thus as a point, or as something which is continuing to occur, thus as a period (admittedly as a short one). It is clearer that noon and midnight indicate points, at least theoretically. The problem with midnight as a time point is its exact determination with the traditional means available. In examining the different terms for noon and midnight, I cannot detect any elements which would seriously speak against their intrepretation as points. One myth from the San Pablo area, however, has the sun god rest atop his house at noon for an hour (here the European concept is used) (Köhler, 1977: 107). Nonetheless this should not be taken as a serious objection. The point concept apparently also characterizes the two positions between horizon and meridian $(3 a, 7 c)$. These points are however not easily determined in practice. In their actual application these terms likely refer to short phases lasting about a half hour to an hour. With respect to the cock's crow, the question arises whether the term refers to a single crow, or, and more probably, to a sequence of crowing.

It can thus be seen that indeed there are indications for the existence of points or point-like phases within the sequence of day and 
night. ${ }^{28}$ At first glance it appears that the distances between the points is symmetrical (disregarding the cock-crow terms). However, the distribution cannot be equal since the lengths of daylight and night change considerably at the latitude of 17 . Only during the equinoxes would this be possible.

All other terms in the sequence refer to periods and not points. This is especially clear when a continuing movement is described, such as the two afternoon subdivisions $(6,7)$. The movement criteria also applies to the time after sunrise (2) which is described either as ascending or as a position quite high in the sky. The wording of the latter description could suggest that it represents a point in time, but this is not clearly specified and in practice the phase lasts for about two consecutive hours around nine o'clock in the morning. The beginning and the end of this phase are neither set nor connected with the surrounding phases. It is an open-ended period which is preceeded and followed by blank, undetermined spaces (see figure 1). The characterization of this phase is also the same for two lengthy phases in the afternoon. At night there are also open-ended periods, yet at dusk and dawn the phases are so close to each other that some degree of overlapping occurs. This is particuarly evident with "getting dark" and "beginning night" $(10,11)$ and the different shades of early dawn.

To summarize, there are two types of periods, longer periods, lasting about two hours, such as those in the morning and afternoon $(2,6$, $7)$, and shorter periods which precede either the focal points $(5,8,14)$ or the aurora (21). If the cock-crowing phases are interpreted as periods, they would belong to the shorter type.

The character of the individual phases and their relation to each other is shown in figures 1 and 2 . Their differing lengths and the blank spaces between them are immediately apparent. The zigzag lines at both ends of the periods indicate that their delimitation is not exact. The three dots at sunrise, sunset and each of the two quarters symbolize changes in the length of day throughout the seasons. Consequently, the distances between these phases with three dots and with noon extend or shrink according to the annual astronomical cycle. ${ }^{29}$ Perhaps

${ }^{28}$ In figures 1 and 2 their numeration is below the respective arch while the numbers referring to periods are above them.

${ }^{29}$ Precisely this instability is the reason why it is impossible to envision on the basis of these points in time a cycle of subdivisions of uniform lengths. Peoples of the Old World were confronted with the same problem, and uniform hours appeared only after the invention of mechanical clocks (Aveni, 1990: 89-97). 


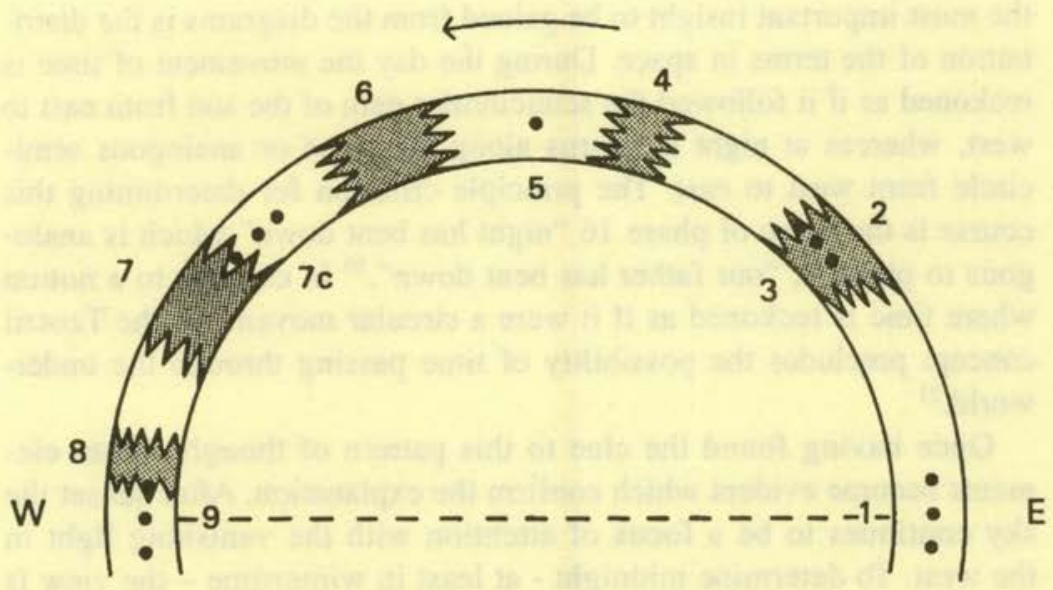

Fig. 1. Subdivision of the day

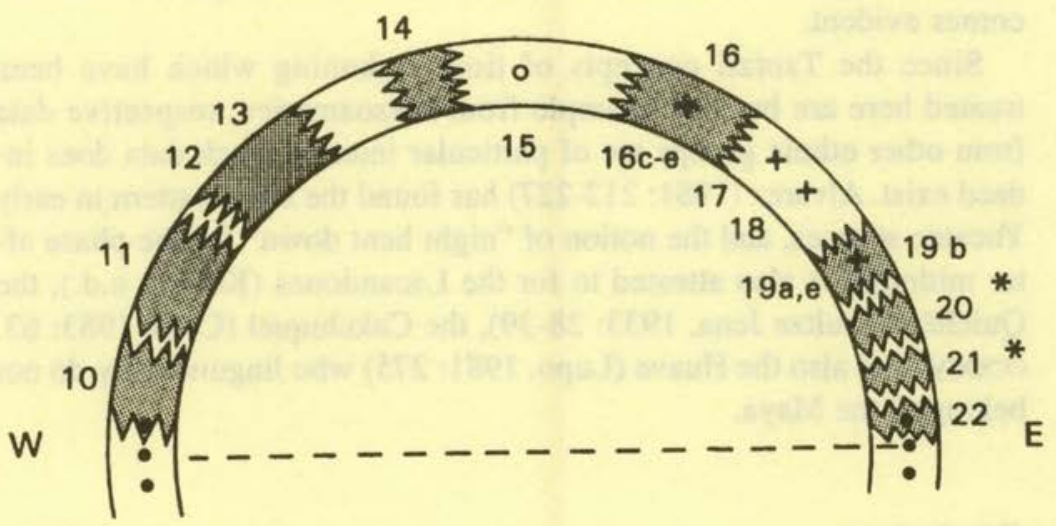

- punto

$+=$ cock-crow

* = relation to star

0 = theoretical point

Fig. 2. Subdivision of the night 
the most important insight to be gained from the diagrams is the distribution of the terms in space. During the day the movement of time is reckoned as if it followed the semicircular path of the sun from east to west, whereas at night it returns along the same or analogous semicircle from west to east. The principle criterion for determining this course is the name of phase 16 "night has bent down" which is analogous to phase 6, "our father has bent down" ${ }^{30}$ In contrast to a notion where time is reckoned as if it were a circular movement, the Tzotzil concept precludes the possibility of time passing through the underworld. ${ }^{31}$

Once having found the clue to this pattern of thought, other elements become evident which confirm the explanation. After sunset the sky continues to be a focus of attention with the vanishing light in the west. To determine midnight - at least in wintertime - the view is directed toward the region around the zenith and the position of the Pleiades. After midnight, the night bends down and then the respective morning star on the eastern sky becomes the pivot. After that and for the distance further down toward the horizon, the new light and the expectation of the rising sun finally become the focus of attention. The logic of the semicircle from west to east (figure 2) thus becomes evident.

Since the Tzotzil concepts of time reckoning which have been treated here are but one example from Mesoamerica, respective data from other ethnic groups are of particular interest. Such data does indeed exist. Alvarez (1981: 212-227) has found the same pattern in early Yucatec sources, and the notion of "night bent down" for the phase after midnight is also attested to for the Lacandones (Köhler, n.d.), the Quiché (Schultze Jena, 1933: 28-39), the Cakchiquel (Coto, 1983: 63, CCXXIv) and also the Huave (Lupo, 1981: 275) who linguistically do not belong to the Maya.

\section{Conclusions}

Although the data was collected in four different Tzotzil "municipios" a common pattern has emerged. The system which subdivides daytime

\footnotetext{
${ }^{30}$ It is recalled that both synonyms $n i^{\prime} p^{\prime} u h$ and $t z^{\prime} e^{\prime} p^{\prime} u h$ refer to a downward movement (cf. footnote 12).

${ }^{31}$ Every Tzotzil knows, of course, that the sun is at night in the underworld, but for them this is simply no criterion for time reckoning.
} 


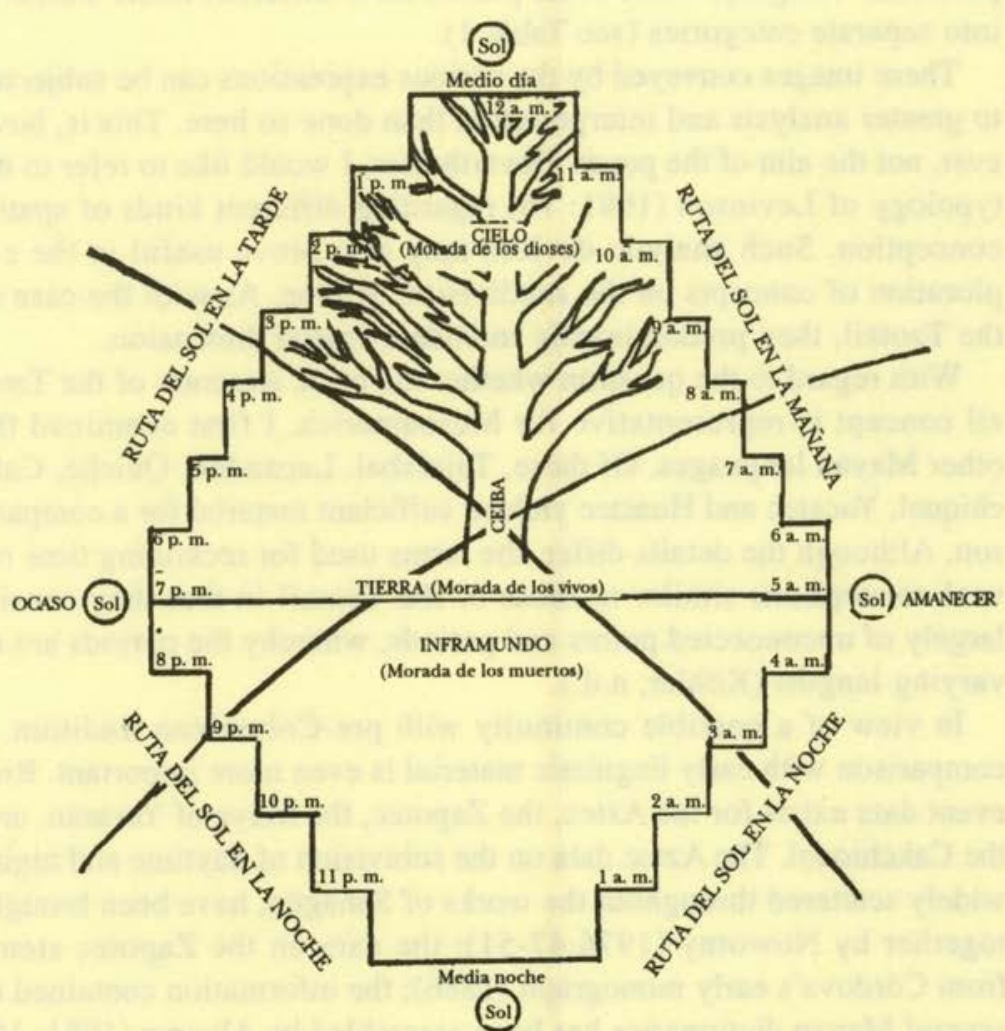

Fig. 3. Tzotzil cosmovision according to Holland

and night is characterized by a combination of points in and periods of time. The periods are open-ended and of various lengths, most of them unconnected, only some partially overlap. Periods and points are nowhere directly connected with each other. Since the time points in the sequence are not equally distributed among each other, the Tzotzil system of dividing up the day is not suitable for generating a mathematical system of reckoning time. From this description it is apparent that there are no hours of equal lengths as in the modern European concept.

Six categories were determined which embrace the various images used in the descriptive terms. Some phases pertain exclusively to a 
particular category, while other phases have different terms which fit into separate categories (see Table 1).

These images conveyed by the various expressions can be subjected to greater analysis and interpretation than done so here. This is, however, not the aim of the paper. Nevertheless, I would like to refer to the typology of Levinson (1991: 16) regarding different kinds of spatial conception. Such analytic devices may also prove useful in the exploration of concepts on the subdivision of time. As with the case of the Tzotzil, they predominantly include a spatial dimension.

With regard to the question whether the basic structure of the Tzotzil concept is representative for Mesoamerica, I first examined the other Mayan languages. Of these, Tojolabal, Lacandon, Quiché, Cakchiquel, Yucatec and Huastec yielded sufficient material for a comparison. Although the details differ, the terms used for reckoning time reveal conceptions similar to those of the Tzotzil in that they consist largely of unconnected points and periods, whereby the periods are of varying lengths (Köhler, n.d.).

In view of a possible continuity with pre-Columbian tradition, a comparison with early linguistic material is even more important. Relevant data exists for the Aztec, the Zapotec, the Maya of Yucatán, and the Cakchiquel. The Aztec data on the subivision of daytime and night, widely scattered throughout the works of Sahagún, have been brought together by Nowotny (1976:47-51); the data on the Zapotec stems from Córdova's early monograph (1886); the information contained in several Mayan dictionaries has been assembled by Alvarez (1981: 1928 ); and the information on the Cakchiquel is from the early dictionary of Coto (1983). The respective concepts place differing emphasis on periods and points; as in all other above mentioned languages, there is, however, no trace of hours of equal lengths. Since the sources cover the three principal linguistic families of Mesoamerica, we may thus conclude that this structure represents a typical pattern for that area.

Let us return now to the initial question of whether the model of the universe, as suggested by Seler and Holland, is valid. Their allocation of the various skies and underworlds as consecutive steps, each representing one hour (figure 3), presupposes the existence of such hours. Since indigenous Mesoamerican systems of subdividing daytime and night have a completely different structure without the slightest affinity to hours of equal lengths, the only possible conclusion is that the model of the universe is an erroneous construction. It is the product of minds who were enculturated with the modern European concept of subdivid- 
ing time, and precisely for that same reason have Western scholars wholeheartedly applauded it. The hour concept is, however, completely alien to indigenous Mesoamerican thought.

Furthermore, at least among the Tzotzil and the other ethnic groups mentioned in that context, the sequence of daytime and night is not conceived of as a full circle. All points of reference for defining the subdivision of the night are above or, at least, on the earth. None are in the underworld. This is an additional argument that refutes the dual pyramid model of Seler and Holland. In order not to promote any further publicity for that appealing trap, the model in figure 3 has been crossed out.

\section{References Cited}

ALCORN, Janis B.

1984 Huastec Mayan Ethnobotany. Austin.

Alvarez, Cristina

1980 Diccionario etnoligüístico del idioma maya yucateco colonial. Volumen I: Mundo fisico. Mexico.

AVENI, Anthony F.

1990 Empires of Time. Calendars, Clocks, and Cultures. London.

CORDOVA, Juan de

1886 Arte del idioma zapoteco. Morelia.

Coto, fray Thomas de

1983 [Thesaurus Verborum]. Vocabulario de la lengua cakchiquel y guatemalteca, nueuamente hecho y recopilado con summo estudio, trauajo y erudición. Mexico.

FloRescano, Enrique

1992 Tiempo, espacio y memoria histórica entre los mayas. Serie Antropología Chiapas 3. Tuxtla.

GeLL, Alfred

1992 The Anthropology of Time. Cultural Constructions of Temporal Maps and Images. Oxford/Providence.

HEYDEN, Doris

1972 What is the significance of the Mexica pyramid? In: Atti del $X L$ Congresso Internazionale degli Americanisti, I: 109-115. Genoa. 
Holland, William $\mathrm{H}$.

1963 Medicina maya en los altos de Chiapas. Un estudio del cambio socio-cultural. México.

1964 Conceptos cosmológicos tzotziles como una base para interpretar la Civilización Maya Prehispánica. America Indigena, 24: 11-28. Mexico.

Hurley vda. de Delgaty, Alfa, y Agustin Ruiz Sanchez

1978 Diccionario Tzotzil de San Andres con Variaciones Dialectales. Mexico.

KOHLER, Ulrich

1974 Huitzilopochtli und die präkolumbische Einteilung des Kosmos in links und rechts. Eine Kritik gängiger Lehrmeinungen. In: Atti del XL Congresso Internazionale degli Americanisti, II: 321-328. Genoa.

1977 Chonbilal Ch'ulelal. Grundformen mesoamerikanischer Kosmologie und Religion in einem Gebetstext auf Maya-Tzotzil. Acta Humboldtiana, 5. Wiesbaden.

1982 Räumliche und zeitliche Bezugspunkte in mesoamerikanischen Konzepten vom Mondzyklus. Mit neuem Quellenmaterial von den Tzotzil. In: Indiana, 7: 23-42. Berlin.

1991 Conceptos acerca del ciclo lunar y su impacto en la vida diaria de indígenas mesoamericanos. In: Johanna Broda, Stanislaw Iwaniszewski y Lucrecia Maupomé (eds.), Arqueoastronomia y Etnoastronomia en Mesoamerica, pp. 235-248. Mexico.

n.d. La subdivisión de dia y noche en idiomas mayances. Actas del Segundo Congreso Internacional de Mayistas (Merida, Yucatan, 24-29 August 1992). Mexico (in press).

LAUGHLIN, Robert M.

1975 The Great Tzotzil Dictionary of San Lorenzo Zinacantan. Smithsonian Contributions to Anthropology 19. Washington.

1988 The Great Tzotzil Dictionary of Santo Domingo Zinacantan. Vol. I-III. Smithsonian Contributions to Anthropology 31. Washington.

Levinson, Stephen C.

1991 Primer for the Field Investigation of Spatial Description and Conception. Cognitive Anthropology Research Group, Working Paper No. 5. Nijmegen.

Lowe, Gareth W.

1982 Izapa Religion, Cosmology, and Ritual. In: Gareth W. Lowe, Thomas A. Lee, Jr., and Eduardo Martínez Espinoza: Izapa: An Introduction to the Ruins and Monuments, pp. 269-305. Papers of the New World Archaeological Foundation 31. Provo, Utah. 
LuPo, Alessandro

1981 Conoscenze astronomiche e concezioni cosmologiche dei Huave di San Mateo del Mar (Oaxaca, Messico). In: L'Uomo, 5, 2: 267-314.

MunN, Nancy D.

1992 The Cultural Anthropology of Time: A Critical Essay. In: Annual Review of Anthropology 21: 93-123. Palo Alto.

Nowotny, Karl A.

1976 Der indianische Ritualismus. Dokumente der Geistesgeschichte 4. Köln.

Schultze JenA, Leonhard

1933 Leben, Glaube und Sprache der Quiché von Guatemala. Indiana I. Jena.

SELER, Eduard

1902- Gesammelte Abhandlungen zur Amerikanischen Sprach- und 1923 Altertumskunde. Vol. I-V. Berlin.

TEDLOCK, Barbara

1992s Time and the Highland Maya. Albuquerque.

TiBon, Gutierre

1981 El ombligo, como centro cósmico. Una contribución a la historia de las religiones. Mexico.

Villa Rojas, Alfonso

1968 Apendice: Los conceptos de espacio y tiempo entre los grupos mayances contemporaneos. En: Miguel Leon-Portilla, Tiempo y realidad en el pensamiento maya. Ensayo de acercamiento, pp. 119-167. Mexico.

VogT, Evon Z.

1969 Zinacantan. A Maya Community in the Highlands of Chiapas. Cambridge.

n.d. Zinacantec Astronomy, 23 pp. (forthcoming) 